\title{
Common endocrine disorders associated with the polycystic ovary syndrome
}

\author{
Ibrahim A. Abdelazim ${ }^{1,2}$, Osama O. Amer ${ }^{3}$, Mohamed Farghali ${ }^{1}$ \\ ${ }^{1}$ Department of Obstetrics and Gynecology, Ain Shams University, Cairo, Egypt \\ ${ }^{2}$ Department of Obstetrics and Gynecology, Ahmadi Hospital, Kuwait Oil Company, Ahmadi, Kuwait \\ ${ }^{3}$ Department of Obstetrics and Gynecology, Ghamra Military Hospital, Cairo, Egypt
}

\begin{abstract}
Introduction: Screening of polycystic ovary syndrome (PCOS) women for hypothyroidism and hyperprolactinemia was suggested, because the undiagnosed hypothyroidism and hyperprolactinemia can aggravate the PCOS symptoms.

Aim of the study: To determine whether the insulin resistance (IR), hypothyroidism, and hyperprolactinemia are common endocrine disorders associated with the PCOS.

Material and methods: One hundred and twenty PCOS women were compared to 120 non-PCOS controls in this study. Participants' day 2-3 hormonal profile and insulin resistance (IR) using the fasting glucose and fasting insulin were evaluated. Collected data were analyzed to determine whether the IR, hypothyroidism, and hyperprolactinemia are common endocrine disorders associated with the PCOS.

Results: TSH and prolactin were significantly high in PCOS women ( $6.4 \pm 4.2$ and $934 \pm 102.3$, respectively) than controls ( $3.5 \pm 3.3$ and $445 \pm 77.5 \mathrm{mlU} / \mathrm{ml}$, respectively) ( $p=0.004$ and 0.001 , respectively). The PCOS women had significantly high relative risk of IR (RR 3.0 (95\% Cl: 1.9-4.7) $p<0.0001)$, hypothyroidism (RR 3.4; $95 \% \mathrm{Cl}$ : 1.7-6.9) $(p=0.0005)$, and hyperprolactinaemia (RR 3.15; $95 \% \mathrm{Cl}: 1.8-5.6)(p=0.0001)$ than controls. The PCOS women had higher odds of IR (OR 4.8; 95\% Cl: 2.6-8.8) ( $p<0.0001)$, hypothyroidism (OR 4.29; 95\% Cl: 1.9-9.4) $(p=0.0003)$, and hyperprolactinaemia (OR 4.27; $95 \% \mathrm{Cl}: 2.1-8.5)(p<0.0001)$ than controls.

Conclusions: TSH and prolactin were significantly high in studied PCOS women, and $47.5 \%$ of the studied PCOS women had IR. The PCOS women had significantly higher odds and relative risks of IR, hypothyroidism, and hyperprolactinemia than controls. IR, hypothyroidism, and hyperprolactinemia are common endocrine disorders associated with PCOS.
\end{abstract}

Key words: endocrine, disorders, PCOS.

\section{Introduction}

Polycystic ovary syndrome (PCOS) affects $15-20 \%$ of women when the ESHRE/ASRM diagnostic criteria used [1]. PCOS has reproductive manifestations (anovulation, and hyperandrogenism), and adverse metabolic outcome (insulin resistance - IR and glucose intolerance) [1-3].

PCOS occurs following interaction of the genetic mutation with the hypothalamo-pituitary dysfunction [2]. An aromatase enzyme genetic mutation was suggested as a cause of PCOS in some studies [4-5], and a recent research showed that the PCOS women with CYP17 gene mutation had significantly higher total testosterone, and clinical features of hyperandrogenism than PCOS women with wild, and heterozygous genotype [6].
In addition, Kshetrimayum et al. suggest that the genetic/host, and the environmental/lifestyle factors might be related to the pathophysiology of PCOS after prenatal exposure to androgen [7].

Fifty-six percent $(56 \%)$ of the PCOS women had evidence of hypothyroidism [8]. The elevated thyrotropin-releasing hormone (TRH) in hypothyroidism acts as dopamine antagonist with subsequent hyperprolactinemia [9]. Abdelazim and Kanshaiym recommended screening of PCOS women for the hypothyroidism, and hyperprolactinemia because the undiagnosed hypothyroidism, and hyperprolactinemia can aggravate the PCOS symptoms [10]. Therefore, this study designed to determine whether the IR, hypothyroidism, and hyperprolactinemia are common endocrine disorders associated with the PCOS. 


\section{Material and methods}

One hundred and twenty (120) PCOS women were included in this prospective multicenter study and compared with 120 non-PCOS controls to determine whether the IR, hypothyroidism, and hyperprolactinemia are common endocrine disorders associated with the PCOS.

Women with endocrine disorders (thyroid, adrenal, prolactin) received contraceptives pills, corticosteroids, or ovulation induction during last 6 months were excluded from this study.

Participants evaluated thoroughly to detect their body mass index (BMI), waist circumference (WC), and the ultrasound criteria of polycystic ovaries.

Participants' day 2-3 hormonal profile (luteinizing hormone - $\mathrm{LH}$, follicle stimulating hormone - FSH, thyroid stimulating hormone - TSH, prolactin, testosterone, androstenedione, 17-hydroxy $(\mathrm{OH})$ progesterone, and dehydroepiandrosterone - DHEA) with fasting glucose and insulin were also evaluated. Any hormonal deviation from the normal range confirmed by a second laboratory result 8 weeks apart. Fasting glucose $(\mathrm{G})$ divided by fasting insulin (I) to get the $G / I$ ratio $(G / I$ ratio $<4.5$ is a useful screening for IR) [3].

The diagnosis of PCOS was based on the ESHRE/ ASRM criteria [11]. The BMI calculated using the body weight divided by the square length $\left(\mathrm{kg} / \mathrm{m}^{2}\right)$ [2]. The WC measured between the upper margin of iliac crest, and lower costal margin (>35 inches means increased WC) [2].

The polycystic ovaries diagnosed by ultrasound following detection of $\geq 12$ follicles in each ovary, each follicle measuring 2-9 $\mathrm{mm}$ and/or increased ovarian volume (>10 ml) according to the Rotterdam ESHRE/ ASRM criteria [11].

However, Teede et al. mentioned that the threshold for polycystic ovarian morphology (PCOM) using the endo-vaginal ultrasound transducers of $8 \mathrm{MHz}$ frequency is $\geq 20$ follicles per ovary and/or an ovarian volume $\geq 10 \mathrm{ml}$ on either ovary, ensuring that there are no corpora lutea, cysts or dominant follicles [12].

Participants with prolactin level double the normal value (normal $<614 \mathrm{mlU} / \mathrm{ml}$ ) evaluated for pituitary adenoma using magnetic resonance imaging (MRI).
Causes of excess androgen such as congenital adrenal hyperplasia (late onset), androgen secreting tumors, and Cushing`s syndrome were excluded before diagnosing PCOS according to the ESHRE/ASRM recommendation [11].

Collected data were analyzed to determine whether the IR, hypothyroidism and hyperprolactinemia are common endocrine disorders associated with the PCOS.

\section{Somple size}

The sample size calculated using the G Power software version 3.17. An effective sample include $>220$ women in two groups (110 PCOS women, and 110 controls) needed to produce a statistically acceptable figure.

\section{Statistical analysis}

Collected data were analyzed using the Statistical Package for Social Science (SPSS) version 23, (Chicago, IL, USA). The Chi-square (X2), and Student $t$-test used to compare the qualitative, and quantitative variables, respectively. Logistic regression analysis used to calculate the relative risk (RR), and Odds ratio (OR) of IR, hypothyroidism, and hyperprolactinemia in PCOS women. The $p$ value $<0.05$ was considered significant.

\section{Results}

One hundred and twenty PCOS women compared with 120 non-PCOS controls in this study to determine whether the IR, hypothyroidism, and hyperprolactinemia are common endocrine disorders associated with the PCOS.

The $\mathrm{BMI}, \mathrm{LH}$, and $\mathrm{LH} / \mathrm{FSH}$ ratio were statistically high in the studied PCOS-women $(31.5 \pm 5.2,16.3 \pm 5.7$ and $2.3 \pm 3.7$, respectively) than controls $\left(25.5 \pm 4.1 \mathrm{~kg} / \mathrm{m}^{2}\right.$, $6.1 \pm 4.3 \mathrm{mIU} / \mathrm{ml}$ and $1.05 \pm 2.9$; respectively), $(p=0.005$, 0.001 and 0.004 ; respectively). TSH, and prolactin were significantly high in the studied PCOS women (6.4 \pm 4.2

Table 1. Age, BMI, and hormonal profile of the two studied groups

\begin{tabular}{lccc}
\hline Variable & $\begin{array}{c}\text { PCOS women (study group) } \\
(n=120)\end{array}$ & $\begin{array}{c}\text { Non-PCOS controls } \\
(n=120)\end{array}$ & $p$-value (95\% Cl) \\
\hline Age (years) & $22.4 \pm 5.1$ & $24.6 \pm 6.3$ & $0.9(-3.65,2.2,0.74)$ \\
\hline BMl $\left(\mathrm{kg} / \mathrm{m}^{2}\right)$ & $31.5 \pm 5.2$ & $25.5 \pm 4.1$ & $0.005^{*}(4.8,6,7.2)$ \\
\hline FSH $(\mathrm{mlU} / \mathrm{ml})$ & $7.2 \pm 6.1$ & $6.4 \pm 5.6$ & $0.18(-0.69,0.8,2.29)$ \\
\hline LH $(\mathrm{mlU} / \mathrm{ml})$ & $16.3 \pm 5.7$ & $6.1 \pm 4.3$ & $0.001^{*}(8.9,10.2,11.48)$ \\
\hline LH/FSH ratio & $2.3 \pm 3.7$ & $1.05 \pm 2.9$ & $0.004^{*}(0.4,1.25,2.1)$ \\
\hline TSH $(\mathrm{mlU} / \mathrm{ml})$ & $6.4 \pm 4.2$ & $3.5 \pm 3.3$ & $0.004^{*}(1.9,2.9,3.9)$ \\
\hline Prolactin $(\mathrm{mlU} / \mathrm{ml})$ & $934 \pm 102.3$ & $445 \pm 77.5$ & $0.001^{*}(465.7,489,512.3)$ \\
\hline
\end{tabular}

PCOS - polycystic ovary syndrome, $\mathrm{FSH}$ - follicle stimulating hormone, $\mathrm{LH}$ - luteinizing hormone, TSH - thyroid stimulating hormone, $\mathrm{Cl}$ - confidence interval, * significant difference. Student t-test used for statistical analysis. Data presented as mean \pm standard deviation (SD) 
Table 2. Rates of overweight, obesity, waist circumference (WC) > 35 inches, insulin resistance (IR), hypothyroidism, and hyperprolactinemia in the two studied groups

\begin{tabular}{lccc}
\hline Variable & $\begin{array}{c}\text { PCOS women (study group) } \\
(n=120)\end{array}$ & $\begin{array}{c}\text { Non-PCOS controls } \\
(n=120)\end{array}$ & $p$-value \\
\hline $\mathrm{BMI} 25-29.9 \mathrm{~kg} / \mathrm{m}^{2}$ & $42.5(51 / 120)$ & $21.7(26 / 120)$ & $0.01^{*}$ \\
\hline $\mathrm{BMI} \geq 30 \mathrm{~kg} / \mathrm{m}^{2}$ & $39.17(47 / 120)$ & $15.8(19 / 120)$ & $0.002^{*}$ \\
\hline $\mathrm{WC}>35$ inches & $44.17(53 / 120)$ & $19.17(23 / 120)$ & $0.002^{*}$ \\
\hline $\mathrm{Glucose} /$ insulin ratio $<4.5$ & $47.5(57 / 120)$ & $15.8(19 / 120)$ & $0.0001^{*}$ \\
\hline TSH $\geq 4.1 \mathrm{mlU} / \mathrm{ml}$ & $25.8(31 / 120)$ & $7.5(9 / 120)$ & $0.001^{*}$ \\
\hline Prolactin $>614 \mathrm{mlU} / \mathrm{ml}$ & $34.17(41 / 120)$ & $10.8(13 / 120)$ & $0.0005^{*}$ \\
\hline
\end{tabular}

PCOS - polycystic ovary syndrome, TSH - thyroid stimulating hormone. ${ }^{*}$ significant difference. $\chi^{2}$ used for statistical analysis. Data presented as number and percentage (\%)

and $934 \pm 102.3$; respectively) than controls (3.5 \pm 3.3 and $445 \pm 77.5 \mathrm{mlU} / \mathrm{ml}$; respectively), ( $p=0.004$ and 0.001 ; respectively) (Table 1 ).

The rates of over-weight, and obesity were significantly high in the studied PCOS group (42.5\% and $39.17 \%$; respectively) than controls $(21.7 \%$ and $15.8 \%$; respectively), ( $p=0.01$ and 0.002 ; respectively). $44.17 \%$ of the studied PCOS women had WC $>35$ inches compared to $19.17 \%$ of the controls $(p=0.002)$, and $47.5 \%$ of the studied PCOS women had IR compared to $15.8 \%$ of the controls ( $p=0.0001$ ). In addition, $25.8 \%$ of the studied PCOS women had elevated TSH compared to $7.5 \%$ of the controls ( $p=0.001$ ), and $34.17 \%$ of the studied PCOS women had hyperprolactinemia compared to $10.8 \%$ of the controls $(p=0.0005)$ (Table 2 ).

The studied PCOS women had significantly high RR of overweight (RR $1.96(95 \% \mathrm{Cl} ; 1.3-2.9) ; p=0.0009)$, obesity (RR $2.4(95 \% \mathrm{Cl} ; 1.54-3.9) ; p=0.0002)$, WC > 35 inches (RR $2.3(95 \% \mathrm{Cl} ; 1.5-3.5) ; p=0.0001)$, and IR (RR 3.0 (95\% Cl; 1.9-4.7); $p<0.0001)$ than controls. The studied PCOS women had also significantly high RR of hypothyroidism (RR 3.4 (95\% Cl; 1.7-6.9); $p=0.0005)$, and hyperprolactinemia (RR $3.15(95 \% \mathrm{Cl}$; 1.8-5.6); $p=0.0001$ ) than controls (Table 3).

The studied PCOS women had significant higher odds of overweight (OR $2.67(95 \% \mathrm{Cl}$; 1.5-4.7); $p=0.0007)$, obesity (OR $3.4(95 \% \mathrm{Cl}$; 1.85-6.3); $p=0.0001), W C>35$ inches (OR $3.3(95 \% \mathrm{Cl}$; 1.87-5.9; $p<0.0001)$, and IR (OR 4.8 (95\% Cl; 2.6-8.8); $p<0.0001)$ than controls. The studied PCOS women had also significant higher odds of hypothyroidism (OR 4.29 (95\% Cl; $1.9-9.4) ; p=0.0003$ ), and hyperprolactinaemia (OR 4.27 (95\% Cl; 2.1-8.5); $p<0.0001)$ than controls (Table 4).

\section{Discussion}

Fifty-six percent (56\%) of the PCOS women had evidence of hypothyroidism [8]. The elevated thyrotropin-releasing hormone (TRH) in hypothyroidism acts as dopamine antagonist with subsequent hyperprolactinemia [9]. Therefore, one hundred and twenty PCOS women compared with 120 non-PCOS controls in this

Table 3. Relative risk (RR) of overweight, obesity, insulin resistance (IR), hypothyroidism, and hyperprolactinemia in PCOS women

\begin{tabular}{|c|c|c|c|}
\hline Variable & $\begin{array}{l}\text { PCOS women (study group) } \\
(n=120)\end{array}$ & $\begin{array}{c}\text { Non-PCOS controls } \\
(n=120)\end{array}$ & $\begin{array}{c}\text { Relative risk }(95 \% \mathrm{Cl}) ; \\
p \text {-value }\end{array}$ \\
\hline BMI $25-29.9 \mathrm{~kg} / \mathrm{m}^{2}$ & $51(42.5)$ & $26(21.7)$ & 1.96 (1.3-2.9); $0.0009^{*}$ \\
\hline $\mathrm{BMI}<25 \mathrm{~kg} / \mathrm{m}^{2}$ & $69(57.5)$ & $94(78.3)$ & \\
\hline $\mathrm{BMI} \geq 30 \mathrm{~kg} / \mathrm{m}^{2}$ & $47(39.17)$ & $19(15.8)$ & $2.4(1.54-3.9) ; 0.0002^{*}$ \\
\hline $\mathrm{BMI}<30 \mathrm{Kg} / \mathrm{m}^{2}$ & $73(60.83)$ & $101(84.2)$ & \\
\hline$W C>35$ inches & $53(44.17)$ & $23(19.17)$ & $2.3(1.5-3.5) ; 0.0001^{*}$ \\
\hline$W C<35$ inches & $67(55.13)$ & $97(80.83)$ & \\
\hline $\mathrm{G} / \mathrm{I}$ ratio $<4.5$ & $57(47.5)$ & $19(15.8)$ & $3.0(1.9-4.7) ;<0.0001^{*}$ \\
\hline $\mathrm{G} / \mathrm{I}$ ratio $>4.5$ & $63(52.5)$ & $101(84.2)$ & \\
\hline $\mathrm{TSH} \geq 4.1 \mathrm{mIU} / \mathrm{ml}$ & $31(25.8)$ & $9(7.5)$ & $3.4(1.7-6.9) ; 0.0005^{*}$ \\
\hline $\mathrm{TSH}<4.1 \mathrm{mlU} / \mathrm{ml}$ & $89(74.2)$ & $111(92.5)$ & \\
\hline Prolactin > $29 \mathrm{ng} / \mathrm{ml}(>614 \mathrm{mlU} / \mathrm{ml})$ & $41(34.17)$ & $13(10.8)$ & $3.15(1.8-5.6) ; 0.0001^{*}$ \\
\hline Prolactin $<29 \mathrm{ng} / \mathrm{ml}(<614 \mathrm{mlU} / \mathrm{ml})$ & 79 (65.83) & $107(89.2)$ & \\
\hline
\end{tabular}

PCOS - polycystic ovary syndrome, WC - waist circumference, G/l - glucose/insulin, TSH - thyroid stimulating hormone, $\mathrm{Cl}$ - confidence interval. * significant difference. Data presented as number and percentage (\%) 
Table 4. Odds ratio (OR) of overweight, obesity, insulin resistance (IR), hypothyroidism, and hyperprolactinemia in PCOS women

\begin{tabular}{|c|c|c|c|}
\hline Variable & $\begin{array}{l}\text { PCOS women (study group) } \\
(n=120)\end{array}$ & $\begin{array}{c}\text { Non-PCOS controls } \\
(n=120)\end{array}$ & $\begin{array}{c}\text { Odds ratio }(95 \% \mathrm{Cl}) ; \\
p \text {-value }\end{array}$ \\
\hline BMI $25-29.9 \mathrm{~kg} / \mathrm{m}^{2}$ & $51(42.5)$ & $26(21.7)$ & 2.67 (1.5-4.7); 0.0007* \\
\hline $\mathrm{BMI}<25 \mathrm{~kg} / \mathrm{m}^{2}$ & $69(57.5)$ & $94(78.3)$ & \\
\hline $\mathrm{BMI} \geq 30 \mathrm{~kg} / \mathrm{m}^{2}$ & 47 (39.17) & $19(15.8)$ & $3.4(1.85-6.3) ; 0.0001^{*}$ \\
\hline $\mathrm{BMI}<30 \mathrm{Kg} / \mathrm{m}^{2}$ & $73(60.83)$ & $101(84.2)$ & \\
\hline$W C>35$ inches & $53(44.17)$ & $23(19.17)$ & $3.3(1.87-5.9) ;<0.0001^{\star}$ \\
\hline$W C<35$ inches & $67(55.13)$ & $97(80.83)$ & \\
\hline $\mathrm{G} / \mathrm{I}$ ratio $<4.5$ & $57(47.5)$ & $19(15.8)$ & $4.8(2.6-8.8) ;<0.0001^{*}$ \\
\hline $\mathrm{G} / \mathrm{I}$ ratio $>4.5$ & $63(52.5)$ & $101(84.2)$ & \\
\hline $\mathrm{TSH} \geq 4.1 \mathrm{mlU} / \mathrm{ml}$ & $31(25.8)$ & $9(7.5)$ & 4.29 (1.9-9.4); 0.0003* \\
\hline $\mathrm{TSH}<4.1 \mathrm{mlU} / \mathrm{ml}$ & $89(74.2)$ & $111(92.5)$ & \\
\hline Prolactin > $29 \mathrm{ng} / \mathrm{ml}(>614 \mathrm{mlU} / \mathrm{ml})$ & $41(34.17)$ & $13(10.8)$ & $4.27(2.1-8.5) ;<0.0001^{*}$ \\
\hline Prolactin < 29 ng/ml $(<614$ mlU/ml) & $79(65.83)$ & $107(89.2)$ & \\
\hline
\end{tabular}

PCOS - polycystic ovary syndrome, WC - waist circumference, $\mathrm{G} / \mathrm{I}$ - glucose/insulin, TSH - thyroid stimulating hormone, $\mathrm{Cl}$ - confidence interval. * significant difference. Data presented as number and percentage (\%)

study to determine whether the IR, hypothyroidism, and hyperprolactinemia are common endocrine disorders associated with the PCOS.

The odds, and RR of overweight, obesity, and WC $>35$ inches were significantly high in the studied PCOS women than controls. $44.17 \%$ of the studied PCOS women had WC > 35 inches compared to $19.17 \%$ of the controls $(p=0.002)$. Abufaza et al. reported that the PCOS obesity characterized by WC $>35$ inches [2].

About $47.5 \%$ of the studied PCOS women had IR compared to $15.8 \%$ of the controls ( $p=0.0001$ ), and the studied PCOS women had significant higher odds, and RR of IR (OR 4.8; RR 3.0) than controls. IR means decreased glucose response to insulin with subsequent hyperinsulinemia, and utilization of fat as a source of energy (lipolysis), which leads to elevated triglyceride, and decreased HDL-cholesterol, glucose intolerance, and cardiovascular risks [1-3]. Insulin stimulates ovarian androgen production through its direct effect on the $\mathrm{LH}$ receptors of the theca cells with subsequent hyperandrogenism which interferes with ovarian follicle maturation with subsequent anovulation [13].

This explains the relation between hyperinsulinemia, and both hirsutism, and anovulation in PCOS [14]. A positive relation between hyperinsulinemia, and the number of the ovarian follicles reported by Sikka et al. in PCOS women [13].

Mostafa et al. found that about $46 \%$ of PCOS Egyptian women had IR [3]. They also found the hirsutism was significantly high in IR PCOS women compared to non-IR PCOS controls, and they suggested the use of the $G / I$ ratio as a useful screening test for $I R$ in PCOS women [3].

Although, Cho et al. found that the LH/FSH ratio has little use in diagnosing PCOS [15]. The LH, and the LH/FSH ratio were statistically high in the studied
PCOS women than controls. In addition, Nath et al. [8] and Banaszewska et al. [16] also reported an elevated $\mathrm{LH} / \mathrm{FSH}$ ratio in PCOS women.

Recently, Dapas et al. defined 2 distinct PCOS subtypes: a "reproductive" PCOS group, characterized by higher LH, and sex hormone binding globulin (SHBG) levels with relatively low BMI, and insulin levels, and a "metabolic" PCOS group, characterized by higher BMI, glucose, and insulin levels with lower SHBG, and LH levels [17].

The TSH, and prolactin were significantly high in the studied PCOS women than controls ( $p=0.004$ and 0.001; respectively), $25.8 \%$ of the studied PCOS women had elevated TSH compared to $7.5 \%$ of the controls, and $34.17 \%$ of the studied PCOS women had hyperprolactinemia compared to $10.8 \%$ of the controls. The studied PCOS women had also significant higher odds, and RR of hypothyroidism (OR 4.29; RR 3.4), and hyperprolactinaemia (OR 4.27; RR 3.15) than controls.

The high BMI of the PCOS women produces relative thyroid hormone deficiency (sub-clinical hypothyroidism $(\mathrm{SCH})$ ). The non-diagnosed $\mathrm{SCH}$ of the PCOS women converted to overt hypothyroidism with further increase in BMI. Consequently, the overt hypothyroidism, produces anovulation, and increased severity of PCOS symptoms [8].

Enzevaei et al. found that $25.5 \%$ of the PCOS subjects have SCH [18]. Similarly, Sinha et al, reported that $22.5 \%$ of the PCOS subjects have SCH compared to $8.75 \%$ in controls [19].

Cramer et al. explained the association between hypothyroidism, and hyperprolactinemia, and they mentioned that the elevated thyrotropin-releasing hormone in hypothyroidism acts as dopamine antagonist with subsequent hyperprolactinemia [9]. Hyperprolactinaemia produces luteal phase defect, and defective steriodogessis of the two-cell theory with subsequent 
ovarian hyperandrogenism (mainly testosterone and androsetendione), and increased PCOS severity [9].

Similarly, Lerchbaum et al. [20] and Abdelazim et al. [21] found the androstenedione, and testosterone are the main elevated ovarian androgens in PCOS.

This study found that the TSH, and prolactin were significantly high in studied PCOS women, and $47.5 \%$ of the studied PCOS women had IR. The PCOS women had significantly higher odds, and relative risks of $I R$, hypothyroidism, and hyperprolactinemia than controls.

The current study was the first study designed to determine, and explain the association between IR, hypothyroidism, hyperprolactinemia, and PCOS.

Women refused to give consent or to participate was the only limitation faced during this study. Larger future studies needed to confirm the association, and the prevalence of IR, hypothyroidism, and hyperprolactinemia among PCOS women.

\section{Conclusions}

$\mathrm{TSH}$, and prolactin were significantly high in studied PCOS women, and $47.5 \%$ of the studied PCOS women had IR. The PCOS women had significantly higher odds, and relative risks of IR, hypothyroidism, and hyperprolactinemia than controls. IR, hypothyroidism, and hyperprolactinemia are common endocrine disorders associated with PCOS.

\section{Disclosure}

The authors report no conflict of interest.

\section{References}

1. Abdelazim IA, Elsawah WF. Metabolic syndrome among infertile women with polycystic ovary syndrome. Asian Pac J Reprod 2015; 4: 44-48.

2. Abufaza M, Abdelazim I, Purohit P, et al. The diagnosis and the reproductive and metabolic consequences of polycystic ovary syndrome. J Obstet Gynecol Investig 2018; 1: 67-73.

3. Mostafa RA, Al-Sherbeeny MM, Abdelazim IA, et al. Frequency of Insulin Resistance in Egyptian Women with Polycystic Ovary Syndrome. MOJ Womens Health 2015; 1: 00008.

4. Mostafa RA, Al-Sherbeeny MM, Abdelazim IA, et al. Relation between aromatase gene CYP19 variation and hyperandrogenism in polycystic ovary syndrome Egyptian women. J Infert Reprod Biol 2016; 4: 1-5.

5. Chen J, Shen S, Tan Y, et al. The correlation of aromatase activity and obesity in women with or without polycystic ovary syndrome. J Ovarian Res 2015; 8: 11

6. Ashraf S, Rasool SUA, Nabi M, et al. CYP17 gene polymorphic sequence variation is associated with hyperandrogenism in Kashmiri women with polycystic ovarian syndrome. Gynecol Endocrinol 2020. doi: https://doi. org/10.1080/09513590.2020.1770724.

7. Kshetrimayum C, Sharma A, Mishra VV, Kumar S. Polycystic ovarian syndrome: Environmental/occupational, lifestyle factors; an overview. J Turk Ger Gynecol Assoc 2019; 20: 255-263.

8. Nath CK, Barman B, Das A, et al. Prolactin and thyroid stimulating hor mone affecting the pattern of LH/FSH secretion in patients with polycystic ovary syndrome: A hospital-based study from North East India. J Family Med Prim Care 2019; 8: 256-260.
9. Cramer DW, Sluss PM, Powers RD, et al. Serum prolactin and TSH in an in vitro fertilization population: Is there a link between fertilization and thyroid function? J Assist Reprod Genet 2003; 20: 210-215.

10. Abdelazim IA, Kanshaiym S. Abdelazim and Sakiyeva endocrinopathy associated with polycystic ovary syndrome: Case reports. J Family Med Prim Care 2019; 8: 3039-3041.

11. Rotterdam ESHRE/ASRM-Sponsored PCOS Consensus Workshop Group. Revised 2003 consensus on diagnostic criteria and long-term health risks related to polycystic ovary syndrome. Fertil Steril 2004; 81: 19-25.

12. Teede HJ, Misso ML, Costello MF, et al. Recommendations from the international evidence-based guideline for the assessment and management of polycystic ovary syndrome. Fertil Steril 2018; 110: 364-379.

13. Sikka P, Gainder S, Dhaliwal LK, et al. Ultrasonography of the ovaries and its correlation with clinical and endocrine parameters in infertile women with PCOS. Int J Fertil Womens Med 2007; 52: 41-47.

14. Landay M, Huang A, Azziz R. Degree of hyperinsulinemia, independent of androgen levels, is an important determinant of the severity of hirsutism in PCOS. Fertil Steril 2009; 92: 643-647.

15. Cho LW, Jayagopal V, Kilpatrick ES, et al. The LH/FSH ratio has little use in diagnosing polycystic ovarian syndrome. Ann Clin Biochem 2006; 43 (Pt 3): 217-219.

16. Banaszewska B, Spaczyński RZ, Pelesz M, Pawelczyk L. Incidence of elevated LH/FSH ratio in polycystic ovary syndrome women with normo- and hyperinsulinemia. Rocz Akad Med Bialymst 2003; 48: 131-134.

17. Dapas M, Lin FTJ, Nadkarni GN, et al. Distinct subtypes of polycystic ovary syndrome with novel genetic associations: An unsupervised, phenotypic clustering analysis. PLoS Med 2020; 17: e1003132.

18. Enzevaei A, Salehpour S, Tohidi M, Saharkhiz N. Subclinical hypothyroidism, and insulin resistance in polycystic ovary syndrome: is there a relationship? Iran J Reprod Med 2014; 12: 481-486.

19. Sinha U, Sinharay K, Saha S, et al. Thyroid disorders in polycystic ovarian syndrome subjects: A tertiary hospital based cross-sectional study from Eastern India. Indian J Endocrinol Metab 2013; 17: 304-309.

20. Lerchbaum E, Schwetz V, Rabe T, et al. Hyperandrogenemia in Polycystic Ovary Syndrome: Exploration of the Role of Free Testosterone and Androstenedione in Metabolic Phenotype. PLoS One 2014; 9: e108263.

21. Abdelazim IA, Alanwar A, AbuFaza M, et al. Elevated and diagnostic androgens of polycystic ovary syndrome. Menopause Rev 2020; 19: 1-5. 